\title{
A New Name for Wasabia koreana (Brassicaceae) in South Korea
}

\author{
Hyunchur Shin \\ Department of Biology, Soonchunhyang University, Asan, Chungnam 336-745, Korea \\ Young-Dong Kim \\ Department of Life Science, Hallym University, Chunchon, Kangwon 200-702, Korea. \\ ydkim@hallym.ac.kr
}

Abstract. A new name, Cardamine pseudowasabi $\mathrm{H}$. Shin \& Y. D. Kim (Brassicaceae), is proposed for Wasabia koreana Nakai because the transfer of the epithet to Cardamine L. would create a later homonym.

Key words: Brassicaceae, Cardamine, South Korea, Wasabia.

Wasabia koreana Nakai (Nakai, 1935) was originally described as a new species based on the specimen collected around Gwangreung, a famous royal tomb in South Korea. Because the genus Wasabia Matsumura is no longer accepted, Baik et al. (1986) transferred the species to Eutrema R. Brown and proposed a new name, E. koreanum (Nakai) K. Hammer. The plant depicted in the article, however, does not appear to be $W$. koreana but looks very similar to a vegetable species introduced from Japan, W. japonica (Miquel) Matsumura, implying that they referred to the wrong species. Since then, in some regional floras including the Flora of China (Zhou et al., 2001), W. koreana as well as W. japonica are treated as synonyms of E. wasabi (Siebold) Maximowicz. Recently, Al-Shehbaz and Warwick (2005) considered E. wasabi a synonym of E. japonicum (Miquel) Koidzumi since the combination made by Zhou et al. (2001) was based on the nomen nudum Cochlearia wasabi Siebold and is therefore illegitimate. Unfortunately, these changes for $W$. koreana were apparently conducted without referring to the type specimen.

In a taxonomic review of Wasabia koreana, we carefully examined the holotype deposited in TI (Fig. 1) and concluded that Nakai misidentified the species within Wasabia. The type specimen exhibits morphological characters typical of Cardamine L. such as the presence of a long and slender style as well as simple trichomes on the leaf margin (I. A. AlShehbaz, pers. comm.). In addition, the specimen has no mucronate callosities on the leaf margin, which are diagnostic features observed in Eutrema (Zhou et al., 2001). Its transfer to Cardamine is clearly needed.
Because the name C. koreana Nakai (Nakai, 1952) is already taken, we propose a new name for this misplaced species.

Cardamine pseudowasabi H. Shin \& Y. D. Kim, nom. nov. Replaced name: Wasabia koreana Nakai, J. Jap. Bot. 11: 150. 1935, non Cardamine koreana (Nakai) Nakai, Bull. Natl. Sci. Mus. Tokyo 31: 49. 1952. TYPE: Korea. Kyunggi [Gyeonggi]: Gwangreung, Apr. 1934, R. K. Smith 13 (holotype, TI).

Cardamine pseudowasabi H. Shin \& Y. D. Kim most resembles C. yezoensis Maximowicz, but clearly differs from the latter by having simple leaves (including the basal ones; see Fig. 1) and a densely pubescent stem and leaf margin. Moreover, C. yezoensis ranges from Hokkaido to Sakhalin (Bush, 1939; Ohwi, 1985), while the type locality of C. pseudowasabi is far more southern $\left(37^{\circ} \mathrm{N}\right)$. It is known that $C$. yezoensis is variable in leaf shape and trichome density on the leaf and stem (Bush, 1939). The plants of C. pseudowasabi have not been documented from the Gwangreung area since the original gathering, so there is no collection except for the holotype. More collections and extended research including specimens that encompass the entire geographical range of $C$. yezoensis are needed to be certain that $C$. pseudowasabi is not an extreme form of C. yezoensis.

Acknowledgments. The authors thank TI for access to valuable collections, and appreciate the valuable comments by Ihsan Al-Shehbaz and one anonymous reviewer. This work was supported by the Basic Research Program of the Korea Science and Engineering Foundation (R01-2004-000-10712-0) and by the Eco-Technopia 21 project on environmental technology development (05002-0028-0).

\section{Literature Cited}

Al-Shehbaz, I. A. \& S. I. Warwick. 2005. A synopsis of Eutrema (Brassicaceae). Harvard Pap. Bot. 10: 129-135. 

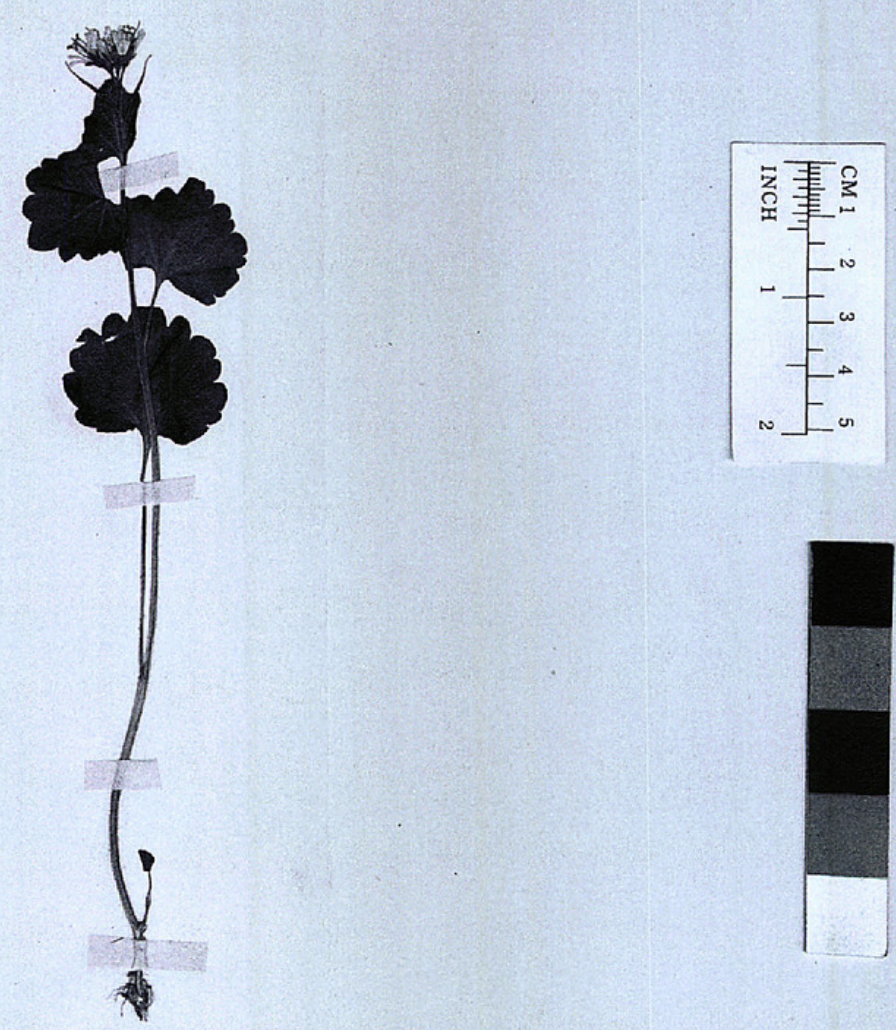

Dept. Botany, Univ. Tokyo

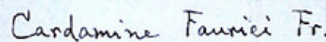

Det. HIROSHI HARA 1976

Herbarium Universitatis Imperialis Tokyoensis
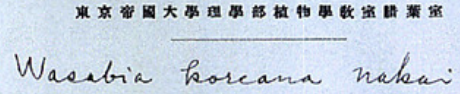

カウアインクサピ

Patria. $\succsim P \frac{5}{2}$

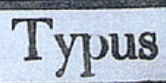

Datum. Aps. 1934.

Legitor. R. K. Smith no.13.

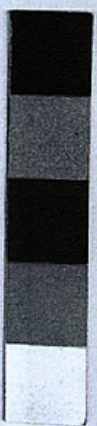

Figure 1. Type specimen of Cardamine pseudowasabi H. Shin \& Y. D. Kim (Smith 13, TI). 
Baik, M-C., H-D. Hoang \& K. Hammer. 1986. A check-list of the Korean cultivated plants. Kulturpflanze 34: 69-144.

Bush, N. A. 1939. Genus Cardamine. Pp. 115-129 in V. L. Komarov (editor), Flora of the U.S.S.R., Vol. 8 (Capparidaceae, Cruciferae, and Resedaceae). [English edition printed in 1985 by Bishen Singh Mahendra Pal Singh, Dehra.]

Nakai, T. 1935. Some noticeable Japanese plants (I). J. Jap. Bot. 11: 147-156.
1952. Synoptical sketch of the Korean Flora. Bull. Natl. Sci. Mus. (Tokyo) 31: 1-152.

Ohwi, J. 1985. Flora of Japan. Smithsonian Institute, Washington, D.C.

Zhou, T. Y., L. L. Lu, G. Yang \& I. A. Al-Shehbaz. 2001. Brassicaceae. Pp. 1-193 in Z. Y. Wu \& P. H. Raven (editors), Flora of China, Vol. 8 (Brassicaceae through Saxifragaceae). Science Press, Beijing, and Missouri Botanical Garden, St. Louis. 


\section{$2 \mathrm{BHL}$ Biodiversity Heritage Library}

Shin, Hyunchur and Kim, Young-Dong. 2008. "A New Name for Wasabia koreana (Brassicaceae) in South Korea." Novon a journal of botanical nomenclature from the Missouri Botanical Garden 18, 384-386.

View This Item Online: https://www.biodiversitylibrary.org/item/55381

Permalink: https://www.biodiversitylibrary.org/partpdf/121847

\section{Holding Institution}

Missouri Botanical Garden, Peter H. Raven Library

\section{Sponsored by}

Missouri Botanical Garden

\section{Copyright \& Reuse}

Copyright Status: In copyright. Digitized with the permission of the rights holder.

License: http://creativecommons.org/licenses/by-nc-sa/3.0/

Rights: https://biodiversitylibrary.org/permissions

This document was created from content at the Biodiversity Heritage Library, the world's largest open access digital library for biodiversity literature and archives. Visit BHL at https://www.biodiversitylibrary.org. 